\title{
Turn Your Old Plastic Wastes to New Utensils
}

\section{Mohamed Elkholy*}

Faculty of Engineering, Alexandria University, Alexandria, Egypt

Recycling doesn't have to happen in large buildings through suspicious operations including melting plastic. You can recycle used plastic from different origins completely by yourself to produce creative, colorful, self-made products, and the process is easy, you just need to have the imagination and creativity to see the artifact disappearing under the ordinary plastic object lying innocently in front of you, and most important, you must have the patience to the reuse process itself.. Let's give you some examples, shall we..?

Having a lot of useless plastic bottles and wondering what to do..? That's your thing then: $1 /$ Cut the base of the bottle then pick up from the following ideas what goes right for you (Figures 1-9).

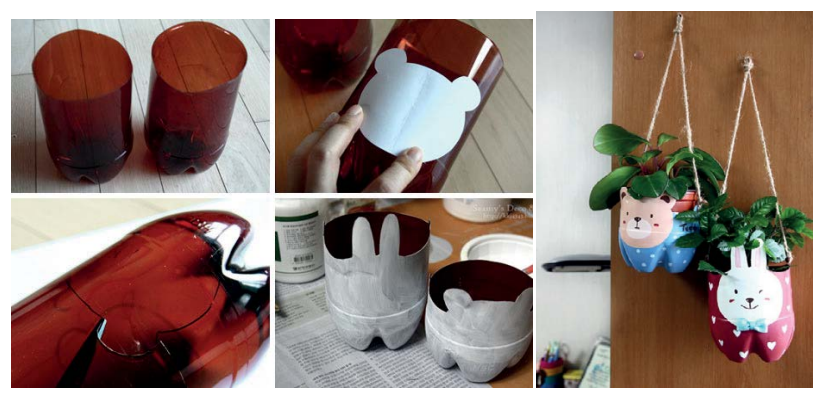

Figure 1: Turn it to a cutie-planter box.

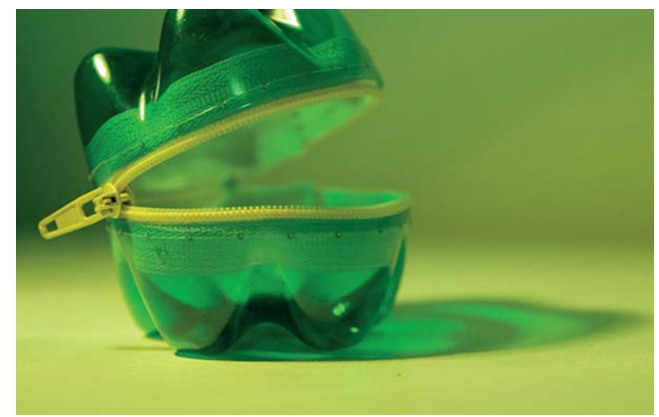

Figure 2: Turn it to a creative purse.

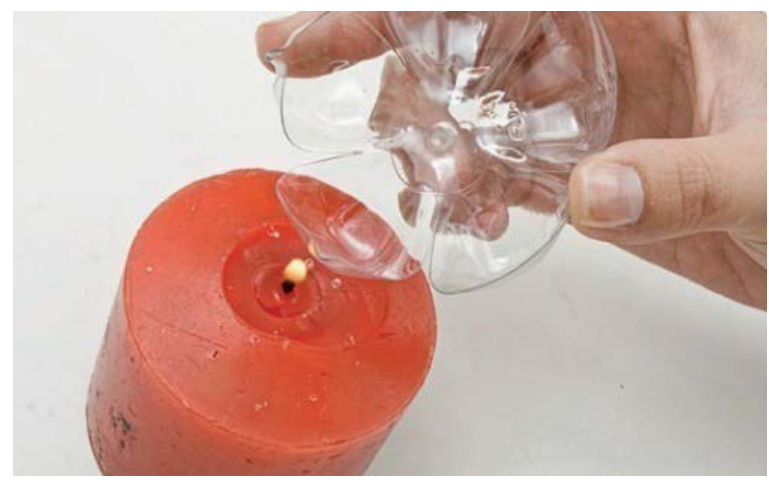

Figure 3: Turn it to a nice candle-box.

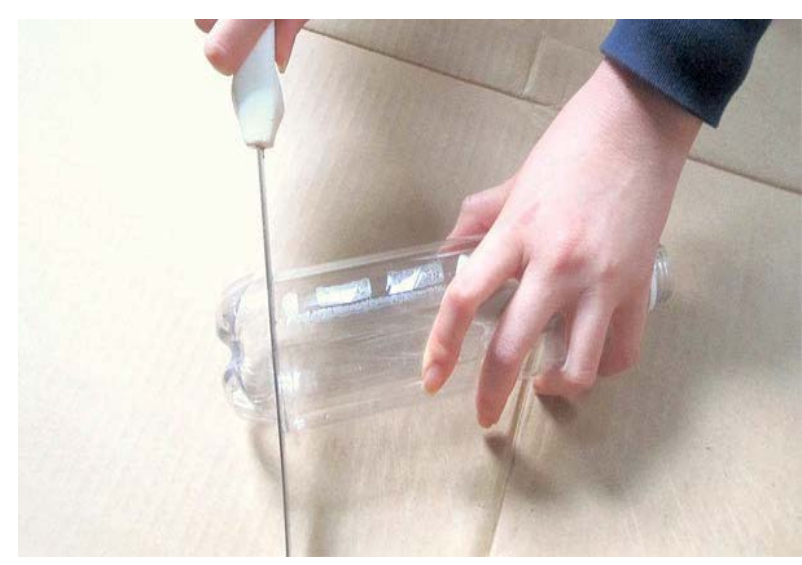

Figure 4: Make your own 1001 bottle-base-chandelier.

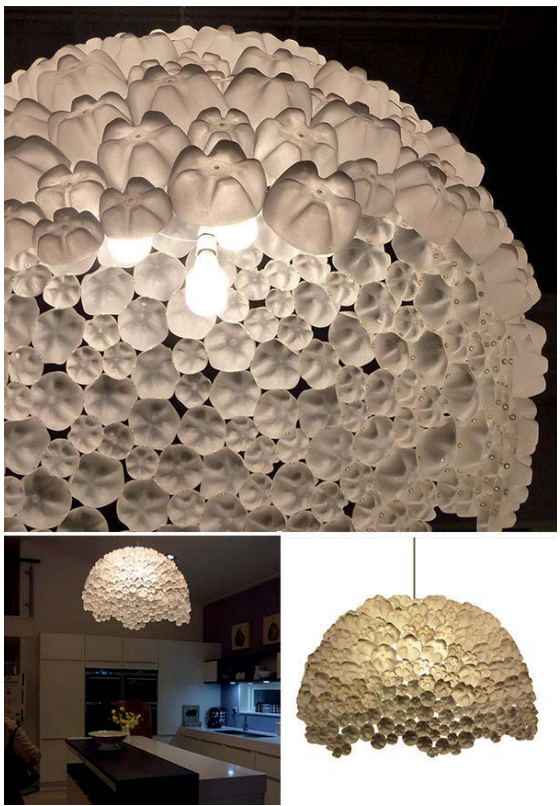

Figure 5: Waste of lights.

*Corresponding author: Elkholy M, Faculty of Engineering, Alexandria University, Alexandria, Egypt, Tel: 02-2274-7078; E-mail: mohamed6j1986@yahoo.com

Received July 18, 2016; Accepted August 03, 2016; Published August 10, 2016

Citation: Elkholy M (2016) Turn Your Old Plastic Wastes to New Utensils. Int J Waste Resour 6: 246. doi: 10.4172/2252-5211.1000246

Copyright: ( 2016 Elkholy M. This is an open-access article distributed under the terms of the Creative Commons Attribution License, which permits unrestricted use, distribution, and reproduction in any medium, provided the original author and source are credited. 


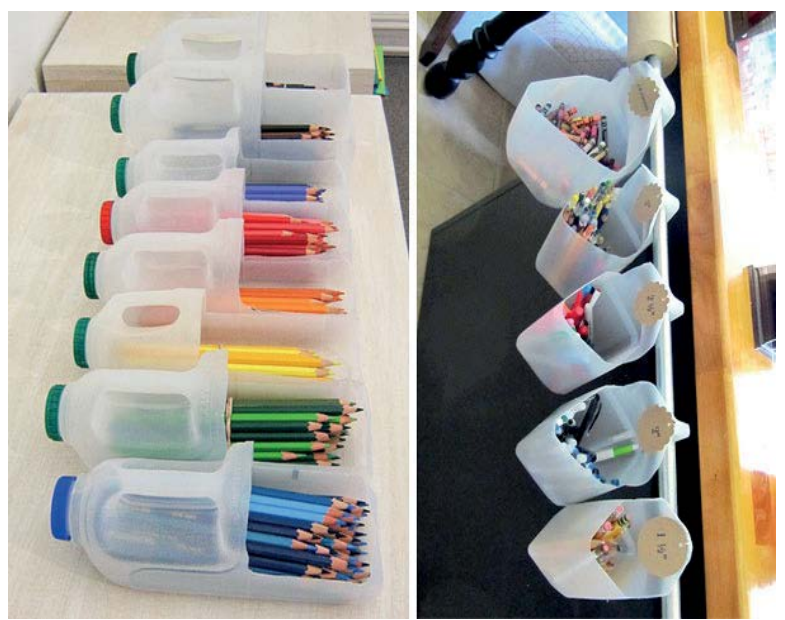

Figure 6: Turn it to your next pens/color organizer.

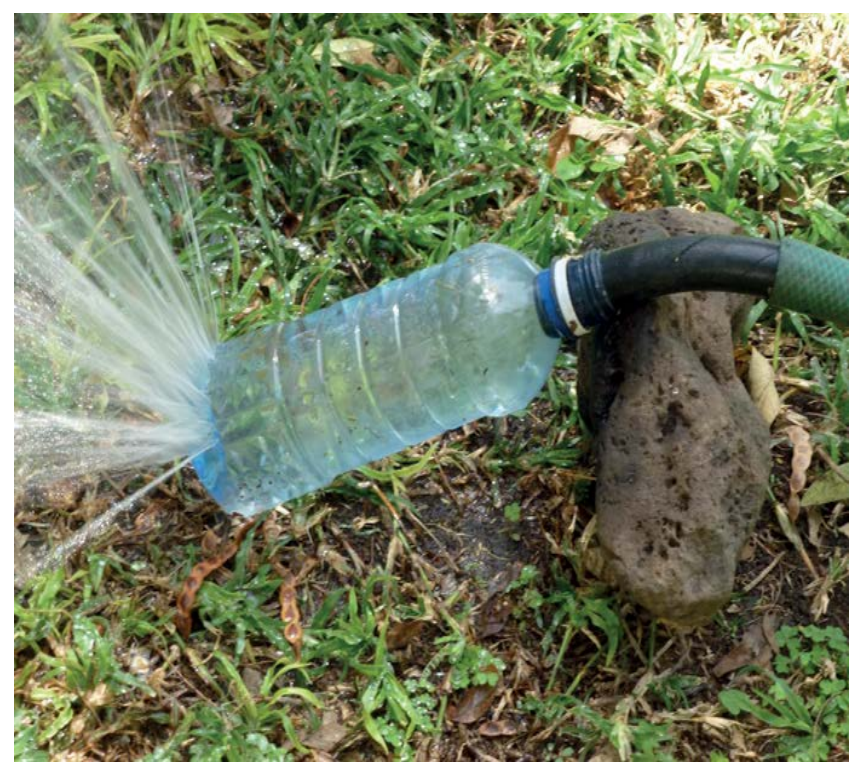

Figure 7: Turn it to your water regulator

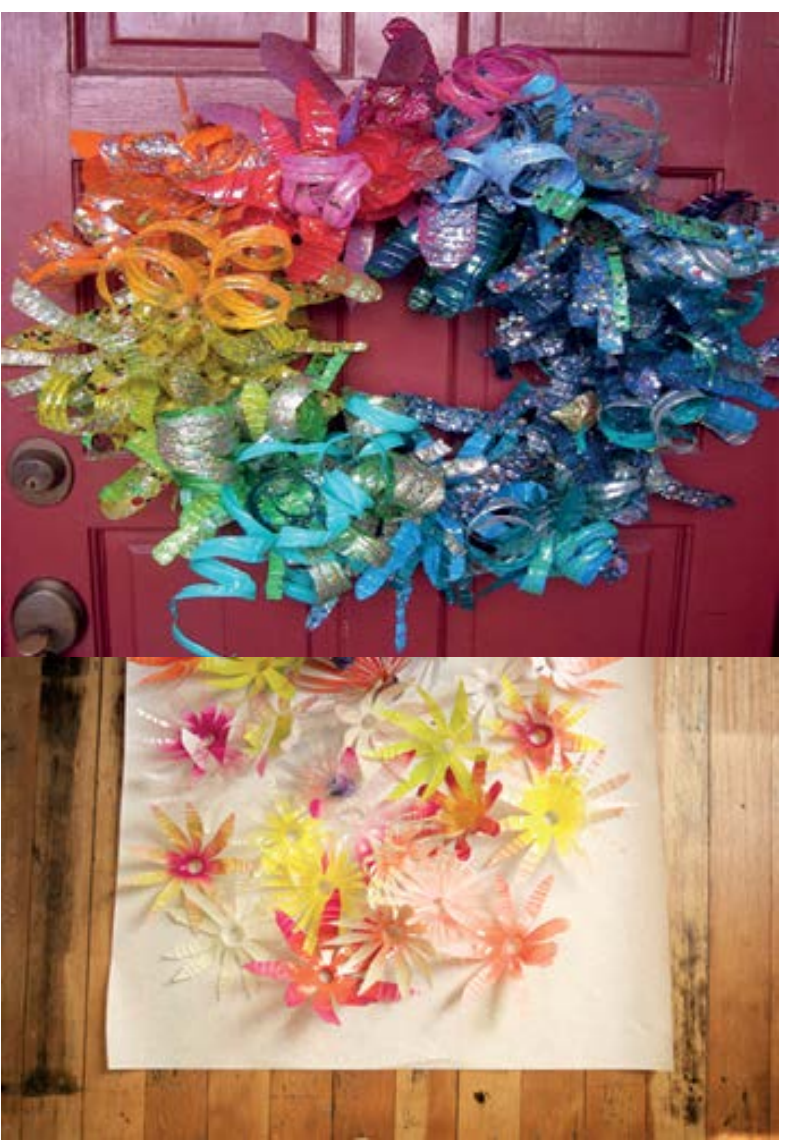

Figure 8: Cut into stings and color them then use as decorations all over you walls.

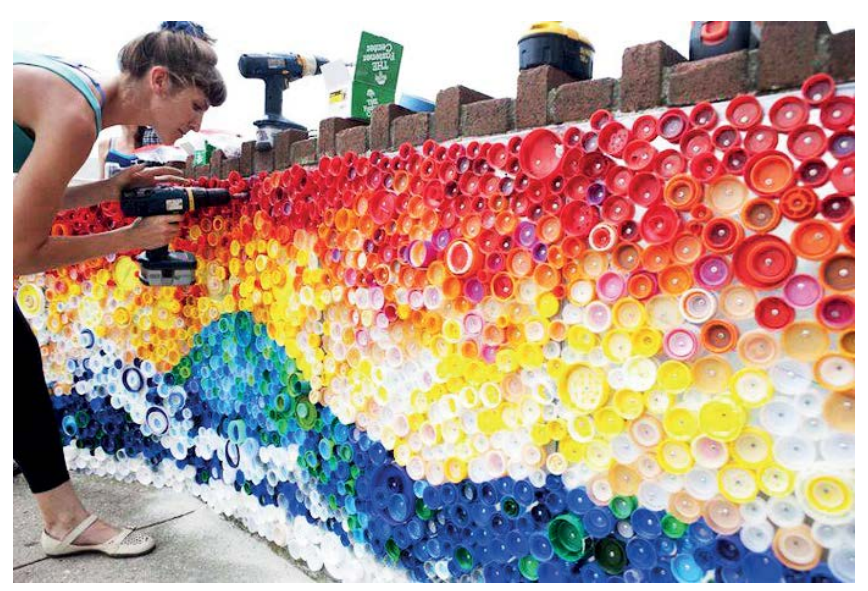

Figure 9: Sticky walls with waste 